\title{
Beyond user experience and technology acceptance: Criteria to select a technology for a road safety behavioural change intervention
}

\author{
DANIEL VANKOV
}

Queensland University of Technology, Centre for Accident Research and Road Safety - Queensland, 130 Victoria Park Road, Kelvin Grove 4059, Queensland, Australia

\begin{abstract}
Novel technologies, such as smartphones or virtual reality, are seen as attractive tools with high potential to trigger behavioral change. Therefore, they are embraced enthusiastically by both business and academia. Interventions using technology as tools can be expected to further increase their popularity in the near future.

A large amount of contemporary research seems to focus on examining user experience and technology acceptance. Such a focus is a natural first step in understanding a novel technology. At the same time, much less is known about the actual effectiveness of novel technologies in interventions. This limited knowledge represents a potential challenge to researchers when deciding which particular technology example to choose for their work.
\end{abstract}

This theoretical study proposes an informed approach to making that choice, particularly for road safety interventions. The approach is grounded in the Theory of Planned Behaviour. Criteria are suggested for initial technology impact evaluation, which should help researchers and practitioners compare different technology examples. Further criteria are touched upon in relation to practicalities around using technologies in interventions. The proposed framework may help future research of technology effectiveness by saving stakeholders' time to decide which technology they should adopt and test.

KEYWORDS: Behavioural change; Novel technologies; Selection criteria; Smartphones; Theory of Planned Behaviour

\section{INTRODUCTION}

In recent years, novel technologies (e.g. smartphones, virtual reality, health trackers, etc.) have been introduced in many aspects of our lives. They claim to answer wants or needs, even when people are not consciously aware of them. Despite such claims, technologies may not be necessarily designed from the perspective of a positive behavioral change. While novel technologies may be quickly adopted in specific fields, such as education (Oyelere et al., 2020), evidence may lack about their impact, such as the case of virtual reality in road safety (Lang et al., 2018; Vankov \& Jankovszky, InPress).

For example, technology applications in road safety are readily available to the general public (Lang et al., 2018; Lee, 2007; Vankov, 2020). They explore serious gaming concepts, i.e. they are arguably designed with a primary goal different from mere entertainment. Gameful designs or gamification may boost motivation and commitment to using such technologies (Diewald, Möller, Roalter, Stockinger, \& Kranz, 2013; Steinberger, Schroeter, Foth, \& Johnson, 2017). Several integrated tools (feedback, challenges, social approval, and rewards) have the potential to trigger a desired positive impact (Diewald et al., 2013; Vankov, Schroeter, \& Twisk, 2021a). However, evidence shows that the positive effects of using such technologies are not guaranteed (Oviedo-Trespalacios, Haque, King, \& Washington, 2016; Vankov et al., 2021a; Vankov, 2020). Understanding the impact of technologies in interventions can be further complicated by high drop-out rates, lack of information on participants' previous familiarity with the technology, or lack of comparison data (Vankov, 2020).

Regardless of limitations, technology can add value to road safety research. Such research often tries to influence the behavior of traffic participants to prevent risky situations.
For example, driving performance is negatively affected by drugs and alcohol (Siliquini et al., 2010). Driving intoxicated increases the risk of crashes (Hingson, Heeren, Levenson, Jamanka, \& Voas, 2002). At the same time, ethical and legal considerations limit the opportunities for such behaviour to be researched (Brookhuis, Waard, \& Samyn, 2004). Novel technology may help open the door for such research to be implemented in safety (Rizzo \& Koenig, 2017; Steinberger et al., 2017; Vankov \& Jankovszky, InPress; Vankov et al., 2021a). However, to the best of the author's knowledge, no systematic approach to select best-suited novel technology tools to trigger behaviour change is available. Hence, their motivation to propose such an approach.

\section{UNDERSTANDING BEHAVIOUR CHANGE}

Research into novel technologies starts with examining user experience and technology acceptance (Vaezipour, 2018; Vankov \& Jankovszky, InPress). After this knowledge is established, the critical question "What is the potential of such technology to impact an individual's behaviour?" remains. To answer this question, an appropriate theoretical grounding can provide a sound basis for an in-depth evaluation, which, in turn, may provide insights on how the desired behavioural change could potentially be motivated (Kohler, Grimley, \& Reynolds, 1999).

Many theories are applied to explore behaviour in scientific interventions in various fields, such as health, human-computer interaction or road safety. A systematic review of 256 articles (8,680 initially retrieved) identified 82 theories in the social and behavioural sciences literature (Davis, Campbell, Hildon, Hobbs, \& Michie, 2015). Three of them accounted for $57 \%$ of the reviewed articles: Transtheoretical model of health 
behavior change (TTM) (Prochaska \& Velicer, 1997) (33\%), Theory of Planned Behaviour (TPB) (Ajzen, 1991) (13\%), and Social Cognitive Theory (SCT) (Bandura, 1986) (11\%). Any of those theories can inform the selection of a technology that has the potential to influence a targeted behaviour positively when utilised as an intervention tool.

\subsection{Transtheoretical model of health behavior change}

TTM (Prochaska \& Velicer, 1997) argues that each individual is in a different stage of behavioural change concerning a specific health-related behaviour. The theory is widely used to explain how people engage in activities to change their behaviour, how they progress through the changes, and what efforts are put in place to maintain new and better behaviour. According to the model, there are six stages of change (Precontemplation (Not Ready); Contemplation (Getting Ready); Preparation (Ready); Action; Maintenance and Termination) (Prochaska \& Velicer, 1997), with the first five being measurable. TTM suggests strategies based on identified individual readiness to change, which can help a person move from one stage to the next. The opposite process (relapse) is also possible at any stage.

TTM is applied in various health-related interventions, such as stress management (Prochaska et al., 2012), reduction of smoking (Prochaska, DiClemente, Velicer, \& Rossi, 1993), improving energy balance (Van Duyn et al., 1998; Velicer et al., 2013) or obesity reduction (Mauriello et al., 2010). In many cases, TTM is used to assess interventions' impact on more than one dimension (e.g. technology, young people and risky behaviour). For example, Prochaska et al. (2012) used a telephone and an online program coaching to improve well-being through improved life evaluation, healthy behaviour, and emotional and physical health. Aveyard et al. (1999) used three TTM-based computer sessions and three class lessons over a year to reduce smoking in young people and their peers. Velicer et al. (2013) implemented a computer-based intervention to prevent substance abuse. Thus, TTM is identified as a helpful model in multidisciplinary research, including human-computer interaction (Aveyard et al., 1999; Di Noia, Contento, \& Prochaska, 2008; Gold et al., 2016) and persuasive technologies that change users' behaviours and attitudes through social influence and persuasion (Fogg, 2009).

Like most models, TTM has attracted criticism (Littell \& Girvin, 2002; West, 2005). Littell and Girvin (2002) see the biggest problem in oversimplifying complex behavioural change processes into stages. Other researchers found instability of the stages themselves (De Nooijer, Van Assema, De Vet, \& Brug, 2005; Hughes, Keely, Fagerstrom, \& Callas, 2005), challenging the model presumption that people make coherent and stable plans. The model also neglects that many health problems arise from semi-automated unhealthy habits, which are not easy to change (West, 2005). For example, Velicer et al. (2013) reported limited results in directly addressing smoking and alcohol. The authors suggested that reactivity and defensiveness towards behavioural change may have been due to the behaviours' addictive nature. So, the model can propose an incorrect intervention strategy for some behaviours (West, 2005).

Regardless of its limitations, TTM could be considered a guiding model to choose best-suited novel technology tools to trigger behaviour change, i.e. tools designed to push participants from one stage to another regarding their risky behaviour. As mentioned earlier, TTM can help measure five different stages. The advantage of TTM is that it aids understanding at which stage of change the study participants are, particularly when dealing with groups that are not homogenous. Thus, relevant questions when evaluating potential technology candidates would be "Does the technology help the user understand at which stage of change they are?" or "Does the technology help the user change their behaviour to move from one stage to another?"

Dividing a participant pool into subgroups, based on their stage, may further allow understanding how effective a respective intervention is in the case of each different stage, i.e. by assessing whether and how far the participants from the respective stage of change progressed as a result of the intervention. As a result, the model could provide valuable information for what type of participants such interventions could deliver maximum benefit.

However, choosing a novel technology for a road safety intervention may often be an early-stage effort. At early stage, it is uncommon to have detailed information about the potential intervention participants that informs at what stage of change they are. Instead, the intervention itself might be used to collect such information. Thus, the initial intervention is more likely not to be stage-tailored.

If tailored, preliminary tailoring to the needs of a specific group of participants carries the risk of the chosen target stage not being identified correctly. Such a shortcoming may be the result of the respective road safety behavioural process potential oversimplification. Furthermore, in road safety, problematic habits in many cases may be semi-automated and, thus, might not be accounted for by the model or the chosen technology it informs.

Finally, TTM focuses on the individual and not on dynamic interpersonal interactions, which are common in road safety. Accounting for interpersonal relations is better to be considered so that normative influences for achieving a positive change can be assessed. Thus, TTM might not be the best initial choice to assess the suitability of novel technology tools to trigger behaviour change.

\subsection{Social Cognitive Theory}

SCT (Bandura, 1986) addresses some TTM limitations. First, the theory looks at the behavioral process as a whole and not as divided into stages. Thus, it can be used to inform interventions with little initial information about its participants. Second, the model goes beyond the limitation of not accounting for interpersonal factors, which are accounted for by its "environment" construct.

SCT (Bandura, 1986) suggests that humans function due to interactions between their environment, personality and behaviour. The theory argues that personality is developed through observational learning and social experience. The environment constitutes the external influences on one's behaviour, while the personality is one's motivational factor to perform the behaviour. The model's personality dimension includes key constructs which influence performing the desired behaviour: 1) self-efficacy or how much an individual believes they can achieve specific goals, outcome expectations or the individual's expectations, in case they perform a behaviour; 2) self-control or how much an individual can autonomously regulate their intentions and behaviours, reinforcements or internal or external responses to an individual's behaviour, affecting their likelihood to continue it; and 3) observational learning or the ability of an individual to reproduce a behaviour after observing it in others. SCT considers both self-reflection, or whether individuals can critically analyse their behaviour, and potential influences of personality characteristics within these constructs. Thus, when evaluating potential technology candidates, a relevant question would be "Does the technology improve the user's ability to understand their behaviour?" or "Does the technology change the user's expectations when performing the behaviour?"

SCT has a long track record of being applied in various fields. The theory informed studies concerned with health 
risks prevention (Miller, Shoda, \& Hurley, 1996; Schwarzer \& Renner, 2000; Wallace, Buckworth, Kirby, \& Sherman, 2000), human-computer interaction (Compeau \& Higgins, 1995; Ifinedo, 2016), young people (Ifinedo, 2016; Wallace et al., 2000) and their peers (Compeau \& Higgins, 1995; Ifinedo, 2016; Rana \& Dwivedi, 2015; Wallace et al., 2000).

While recognising its relative utility, some researchers see SCT as a collection of logical statements that are difficult to test empirically (Smedslund, 1978). Other researchers see its constructs as based on variables that are not well defined and cannot be observed and assessed (Lee, 1989). For example, the instruments to measure self-efficacy may not be carefully developed and validated (Frei, Svarin, Steurer-Stey, \& Puhan, 2009). In addition, Mackenzie (2016) questioned SCT's ability to account for motivation at the moment of executing the behaviour.

The SCT could be considered a guiding model to choose best-suited novel technology tools to trigger behaviour change. The model can inform interventions' evaluation design and can provide insights into the participants' selfefficacy (e.g. how to support personal confidence in achieving behaviour change results or what information to be provided to increase self-reflection), and normative influences (e.g. how to shape the intervention environment to encourage safe behaviour on the road). However, the lack of carefully developed and validated measurement instruments is a notable limitation. Developing and validating questionnaires is more likely to happen after a technology is already chosen as a tool than before that. In addition, the technology could influence participants when they perform risky behaviour. The SCT's questioned ability to account for motivation at the moment of executing the behaviour would challenge its suitability to inform the choice of such technology in the first place. As a result, similar to TTM, SCT might not be the best initial choice to assess the suitability of novel technology tools to trigger behaviour change.

\subsection{Theory of Planned Behaviour}

According to TPB (Ajzen, 1991), future behaviour is best predicted by intention to behave as its immediate antecedent. Intention, in turn, is predicted by three interrelated factors: 1 ) attitude or whether a behaviour is seen as favourable or unfavourable; 2) subjective norm or whether significant others are seen as approving or disapproving the behaviour; and 3) perceived behavioural control (PBC) or whether the behaviour is seen as easy or challenging to perform (Ajzen, 1991). PBC is also seen as directly predicting behaviour.

The TPB components have been used to explain various risk-related behaviours in the health domain, e.g. safer sex, uptake of vitamin C or cycle helmet use (Rutter \& Quine, 2002). Rutter and Quine (2002) overview of evidence suggests that, on average, around $40 \%$ of the variance in both health behaviour and intention can be explained through TPB.

TPB addresses some of the suitability issues identified in TTM and SCT. TPB is not stage-tailored and accounts for interpersonal relations through its subjective norm, addressing the discussed-above TTM limitations of being stage-tailored and focusing on the individual. Despite not being stage-tailored, TPB allows for tailoring strategies to encourage specific behaviour, for example, through interventions, as in Quine, Rutter, and Arnold (2001). There are also validated questionnaires in the TPB toolset, as in Lennon, Oviedo-Trespalacios, and Matthews (2017), Chen et al. (2016), Haque et al. (2012), Elliott and Thomson (2010) and Quine et al. (2001), addressing the discussed SCT limitation of lack of carefully developed and validated instruments.

Similar to TTM and SCT, TPB also suffers from limitations. For example, a criticised TPB assumption is that the theory sees the person as having all the resources and skills to en- act a behaviour of interest (Mackenzie, 2016). Unconscious influences on behaviour (Sheeran, Gollwitzer, \& Bargh, 2013) are also pointed out as a major limitation, as TPB exclusively focuses on rational reasoning. Other researchers underline as a limitation the TPB static explanatory nature (Sniehotta, Presseau, \& Araújo-Soares, 2014). Sniehotta et al. (2014) also suggest that the main problem of TPB is in the validity of its predictions as the sequence of influences it explores conflicts with some available evidence. For example, as a consequence of intervention, shifts in behaviour are not always moderated directly through the TPB constructs (Webb \& Sheeran, 2006). Sometimes, when a habit drives the behaviour, reverse causation is possible (Webb \& Sheeran, 2006). In such cases, intention has little influence on behaviour, and past behaviour is a much stronger predictor of intention and future behaviour (Fishbein \& Ajzen, 2010; Sommer, 2011).

Some of those limitations can be addressed through research design. For example, the static nature limitation could be addressed by a longitudinal design of the studies, exploring shifts in the TPB constructs over time, as in Quine et al. (2001) and Stead et al. (2005). Furthermore, using a technology lends itself to a longitudinal design, making the limitation addressable if the choice of technology accounts for it in the first place.

The assumption that people have the needed resources and skills to enact a behaviour could be addressed by providing research participants with additional resources and skills that could enable them to perform the behaviour of interest. Such resources and skills can be delivered through novel technologies (Steinberger et al., 2017), which support using the TPB for assessing the suitability of novel technology tools to trigger behaviour change.

\subsection{Selecting a theory for a road safety intervention}

All three theories discussed above have a history of being used in the domain of road safety. For example, TTM (Prochaska \& Velicer, 1997) was used to assess interventions for drink drivers (Polacsek et al., 2001), recidivist drink drivers (Freeman et al., 2005) and occupational road safety (Banks, 2008). SCT-based (Bandura, 1986) research investigated mature drivers' attitudes towards speeding and traffic rules violations Tranter and Warn (2008), thrill-seeking, attitudes towards speeding and driving violations (Yıldırım-Yenier, Vingilis, Wiesenthal, Mann, \& Seeley, 2016) and young people's risky driving behaviour (Scott-Parker, 2012). TPB (Ajzen, 1991) informed investigations into speeding (Elliott \& Thomson, 2010; Vankov, Schroeter, \& Twisk, 2021b; Warner \& Åberg, 2008), driving under the influence (Chan, Wu, \& Hung, 2010; Potard, Kubiszewski, Camus, Courtois, \& Gaymard, 2018; Vankov \& Schroeter, 2021) and distraction (Bazargan-Hejazi et al., 2017; Chen et al., 2016).

Exploring all 82 theories or even using the three major ones to select technology as an intervention tool in road safety is beyond the scope of the current article. Thus, based on the above discussion, only an approach building on TPB (Ajzen, 1991), which accounted for 13\% of the articles, second in the ranking (Davis et al., 2015), is discussed in turn.

\section{TPB AND SELECTING A TECHNOLOGY INTERVENTION TOOL IN ROAD SAFETY}

Ajzen (2006) suggests interventions be designed to influence one or more behavioural predictors to change behaviour. Unfortunately, Ajzen (2006) does not specify what interventions (e.g. media campaigns, face-to-face, etc.) may trigger the desired behavioural change. Fife-Schaw, Sheeran, and Norman (2007) agree that TPB is silent in guiding appropriate strategies to influence its basic constructs. Thus, it is left to 
the researchers to establish their criteria while considering the specific needs of their work. To successfully achieve that, they may choose to extend the theory with additional theoretical constructs to improve their model's predictive validity (Elliott \& Thomson, 2010; Scott-Parker, 2012; Vankov $\&$ Schroeter, 2021; Vankov et al., 2021b).

Regardless of the number of additional constructs, which can be used to extend TPB, an intervention cannot be expected to change all of them. For example, no intervention can change demographic variables. Other personality characteristics, such as impulsivity and sensitivity, are not seen as potentially changeable in the short term, either (Scott-Parker, 2012). They are perceived as relatively stable. As a result, researchers should aim to define a viable focus for their interventions to ensure potential success. Regardless that Ajzen (2006) does not provide guidance on what type of intervention should be best to use, he gives some guidance to researchers about their potential interventions' focus. Ajzen (2006) suggests that interventions should focus on salient beliefs, such as the TPB attitude, subjective norm and PBC, as they are readily accessible and might be influenced.

As an example for the current article, we will further build on Ajzen's (2006) suggestion by adding three salient beliefs on top of the TPB attitude, subjective norm and PBC. Those three additional constructs have a history of being used to extend the theory beyond its original constructs (Elliott \& Thomson, 2010; Vankov \& Schroeter, 2021; Vankov et al., 2021b). They are 1) peers' norm, i.e. whether friends or peers are promoting a right or wrong perception of behaviour (Conner \& Sparks, 2005); 2) moral norm, i.e. whether a person sees engaging in a behaviour as appropriate or inappropriate (Conner \& Sparks, 2005), and 3) perceived risk, i.e. whether a person considers the possibility to be involved in a crash or to be caught by the police while performing specific behaviour (Ward et al., 2017). Thus, in our example, we consider six potentially changeable constructs (attitude, subjective norm, PBC, moral norm, perceived risk and peers' norm) to be used to guide the selection of technology for an intervention.

To establish selection criteria, we propose using the constructs' definitions (see Table 1). Those selection criteria can be formulated as binary questions, directly pointing at the respective construct's definition. A positive (yes) answer could carry 1 point. A negative (no) answer should not bring points. Thus, the number of positive responses will determine the relevant technology ranking. Alternatively, a Likert scale can be employed if the compared technologies are too similar. For example, the scale can have seven points, ranging from 1 (not at all) to 7 (very much so) or 1 (definitely not) to 7 (definitely). Adding the points will determine an overall score, allowing the technologies to be ranked. At the next assessment level, whether binary or Likert, multiple experts can assess the technologies. To best account for potential professional bias, we believe that experts with diverse backgrounds should be tasked with the assessment. For example, such expects may come from academia, regulatory bodies, technology companies, road safety not-for-profit activist groups, and representatives from the potential target group. Then, the individual scores of those experts can be averaged to determine the final score for comparison.

Above, we provide a general guideline on approaching the selection of technology for a particular intervention. Nevertheless, a researcher might choose a different theory or different additional predictors depending on their needs (see Understanding behaviour change). For example, suppose there is detailed information about the potential participants, which would allow their stage of behavioural change to be correctly identified. In that case, those participants can be divided into subgroups, and TTM (Prochaska \& Velicer, 1997) can be used to identify novel technologies for each subgroup. Furthermore, if the intervention methodology is established before choosing an appropriate technology, new questionnaires could validate additional constructs. As a result, new SCT-based criteria can be developed. Alternatively, the selected constructs' potential to mediate the desired changes might be considered when assessing the technologies as per the identified TPB selection criteria, as discussed in turn.

For our TPB example, the literature agrees that PBC is a weaker predictor of behaviour than intention (Armitage \& Conner, 2001; Fife Schaw et al., 2007). At the same time, the evidence around predicting intention is mixed. Subjective norm is generally seen as having lower predictive power in TPB than attitude and PBC (Armitage \& Conner, 2001; Fife Schaw et al., 2007). According to Fife Schaw et al. (2007), attitude typically has the strongest predictive value. However, evidence about constructs' predictive power should better be sought case by case for each behaviour of interest. As a result, researchers may wish to assign different weights, i.e. a higher number of points, to the constructs they consider of higher importance.

To show how the above theoretical considerations can be put into practice, we applied the guidelines in selecting a smartphone app as a promising road safety intervention tool in the case of speeding as a targeted behaviour. A review of

\begin{tabular}{|c|c|c|c|}
\hline $\begin{array}{l}\text { Selection } \\
\text { criteria (SC) } \mathbf{N}\end{array}$ & Construct & Definition & Question \\
\hline SC1 & Attitude & $\begin{array}{l}\text { How the user sees the behaviour, favourable or } \\
\text { unfavourable. }\end{array}$ & $\begin{array}{l}\text { Does the technology help the user better see whether } \\
\text { their behaviour is favourable or unfavourable? }\end{array}$ \\
\hline SC2 & $\begin{array}{l}\text { Subjective } \\
\text { norm }\end{array}$ & $\begin{array}{l}\text { Whether the user's significant referents would approve or } \\
\text { disapprove their engagement in a particular behaviour. }\end{array}$ & $\begin{array}{l}\text { Does the technology provide information on how } \\
\text { the user's important referents see their behaviour? }\end{array}$ \\
\hline SC3 & $\mathrm{PBC}$ & $\begin{array}{l}\text { How easy or challenging the user perceives performing } \\
\text { the behaviour. }\end{array}$ & $\begin{array}{l}\text { Does the technology improve the user's ability to } \\
\text { perform the behaviour? }\end{array}$ \\
\hline SC4 & Moral norm & $\begin{array}{l}\text { Whether the user perceives the behaviour as } \\
\text { appropriate or inappropriate. }\end{array}$ & $\begin{array}{l}\text { Does the technology help the user understand } \\
\text { the morality of their behaviour? }\end{array}$ \\
\hline SC5 & Peers' norm & $\begin{array}{l}\text { Whether the user's peers are seen as disapproving or } \\
\text { approving of the respective participant engaging in } \\
\text { the behaviour. }\end{array}$ & $\begin{array}{l}\text { Does the technology provide information on how } \\
\text { the user's peers perform the behaviour? }\end{array}$ \\
\hline SC6 & $\begin{array}{l}\text { Perceived } \\
\text { risk }\end{array}$ & $\begin{array}{l}\text { Whether the driver perceives a risk of being involved in } \\
\text { a crash or being caught by the police while performing } \\
\text { a specific behaviour. }\end{array}$ & $\begin{array}{l}\text { Does the technology provide information on the } \\
\text { possibility the user to be involved in a crash or to be } \\
\text { caught by the police while performing the behaviour? }\end{array}$ \\
\hline
\end{tabular}

Table 1. Technology selection criteria derived from an extended TPB framework. 
TPB studies focused on speeding indicates that PBC, and not attitude, is the strongest predictor of intention (Elliott and Thomson, 2010; Stead et al., 2005; Warner \& Åberg, 2008). While Stead et al. (2005) and Elliott and Thomson (2010) provide support for attitude having the second strongest value and confirm norms as having the lowest contribution, Warner and Åberg (2008) found the reverse. Given that typically PBC is the strongest predictor of intention in the case of speeding, an intervention may focus on using smartphone apps expected to influence PBC. Thus, a positive answer to the PBC-related question should be weighted higher when using the questions as criteria for selecting the most promising technology example.

The next step would be to find out what smartphone software is available that might serve as an intervention tool to influence speeding. In November 2017, we browsed the Google Play and iTunes app stores to identify such smartphone software. The used terms were "road app", "smart driving", "safe driving", and "OBD game". Sixty-six apps from the search results in Google Play and 20 from iTunes were selected for detailed investigation.

The online reviews left by users in the smartphone safedriving apps' marketing profiles were used to screen out smartphone software that was unlikely to be a suitable intervention tool. Thus, the number of apps to be investigated in full detail was narrowed down to six. In Table 2, those apps were scored using the established theoretical selection criteria (see above). Double points were assigned to a positive answer on the PBC-related question because PBC is typically the strongest predictor of speeding.

\begin{tabular}{ll}
\hline Name & Pros \\
\hline Flo - driving & $\begin{array}{l}\text { 1. Can provide live feedback to the driver or can } \\
\text { insights }\end{array}$ \\
& $\begin{array}{l}\text { run invisibly in the background. The life feedback } \\
\text { behaviour and potentially inform conclusions }\end{array}$ \\
& whether it is favorable or unfavorable (SC1). \\
& 2. Provides detailed after-trip feedback on a Google \\
map. This detailed information can potentially & help the driver understand the implications of any \\
changes in their behaviour, thus enabling them to & \\
improve it (SC3). & 3. Offers leaderboard. The leaderboard shows to the \\
driver how their peers are doing (SC5). Comparing \\
with their peers can help the driver assign a moral \\
value to their behaviour (SC4). \\
4. Free for users. \\
5. No geographic restriction. \\
6. Has a web interface. \\
7. Does not need a dongle.
\end{tabular}

AAMI Safe 1. Monitors for exact speed limits, not the general Driver ones. The speed limits feedback can help the driver understand whether it is favorable or unfavorable (SC1).

2. Provides detailed after-trip feedback on a Google map. This detailed information can potentially help the driver understand the implications of any changes in their behaviour, thus enabling them to improve it (SC3).

3. Good mix of gamified elements (scores, badges). Receiving scores and badges can represent a higher morality of the behaviour (SC4).

4. Runs in the background.

5. Does not need a dongle.

6. Free for users.

Cons Scoring

1. Has problems with synchronising with the GPS signal when on autostart.

2. Drivers with short trips may in general score lower than drivers

with long ones.

$\begin{array}{llllll}\text { SC1 } & \text { SC2 } & \text { SC3 } & \text { SC4 } & \text { SC5 } & \text { SC6 } \\ \text { Yes } & \text { No } & \text { Yes } & \text { Yes } & \text { Yes } & \text { No } \\ 1 & 0 & 2 & 1 & 1 & 0\end{array}$

\section{Does not have all car}

manufacturers and models.
Total points: 5
1. Cannot provide real-time

feedback.

2. Fails to record and analyse long journeys.

3. Has problems with synchronising with the GPS signal when on autostart.

4. Very wide thresholds are set for recording an offence.

5. Designed to sell an insurance product.

6. Has problems with calculating the overall score.
Hellas Direct

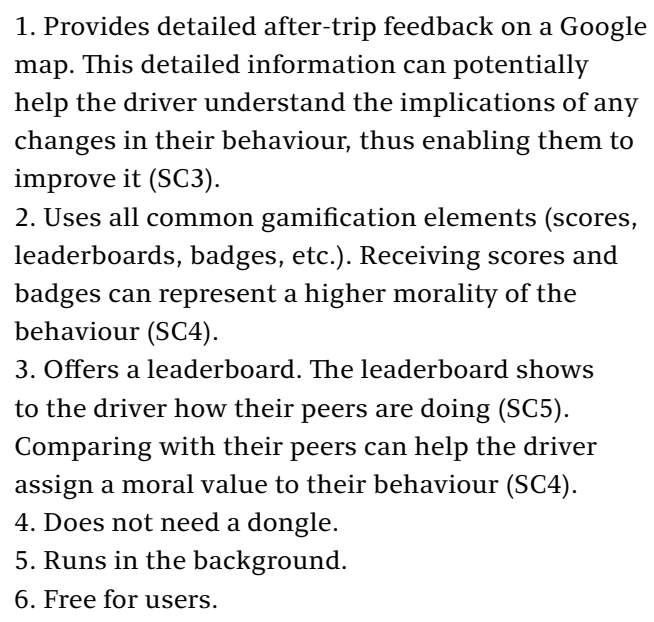

\begin{tabular}{lllllll} 
1. Available only in selected & SC1 & SC2 & SC3 & SC4 & SC5 & SC6 \\
\cline { 2 - 7 } $\begin{array}{l}\text { jurisdictions, i.e. not being tested in } \\
\text { Australia. }\end{array}$ & No & No & Yes & Yes & Yes & No \\
2. Always attached to insurance & 0 & 0 & 2 & 1 & 1 & 0
\end{tabular}
products.

3. Looks like over-gamified - may

Total points: 4

benefit from a "lite" version.

4. Difficult to advise when the user is not the driver.

5. Does not have a user-start option.

\begin{tabular}{llllll} 
SC1 & SC2 & SC3 & SC4 & SC5 & SC6 \\
\hline Yes & No & Yes & Yes & No & No \\
1 & 0 & 2 & 1 & 0 & 0
\end{tabular}

Total points: 4 


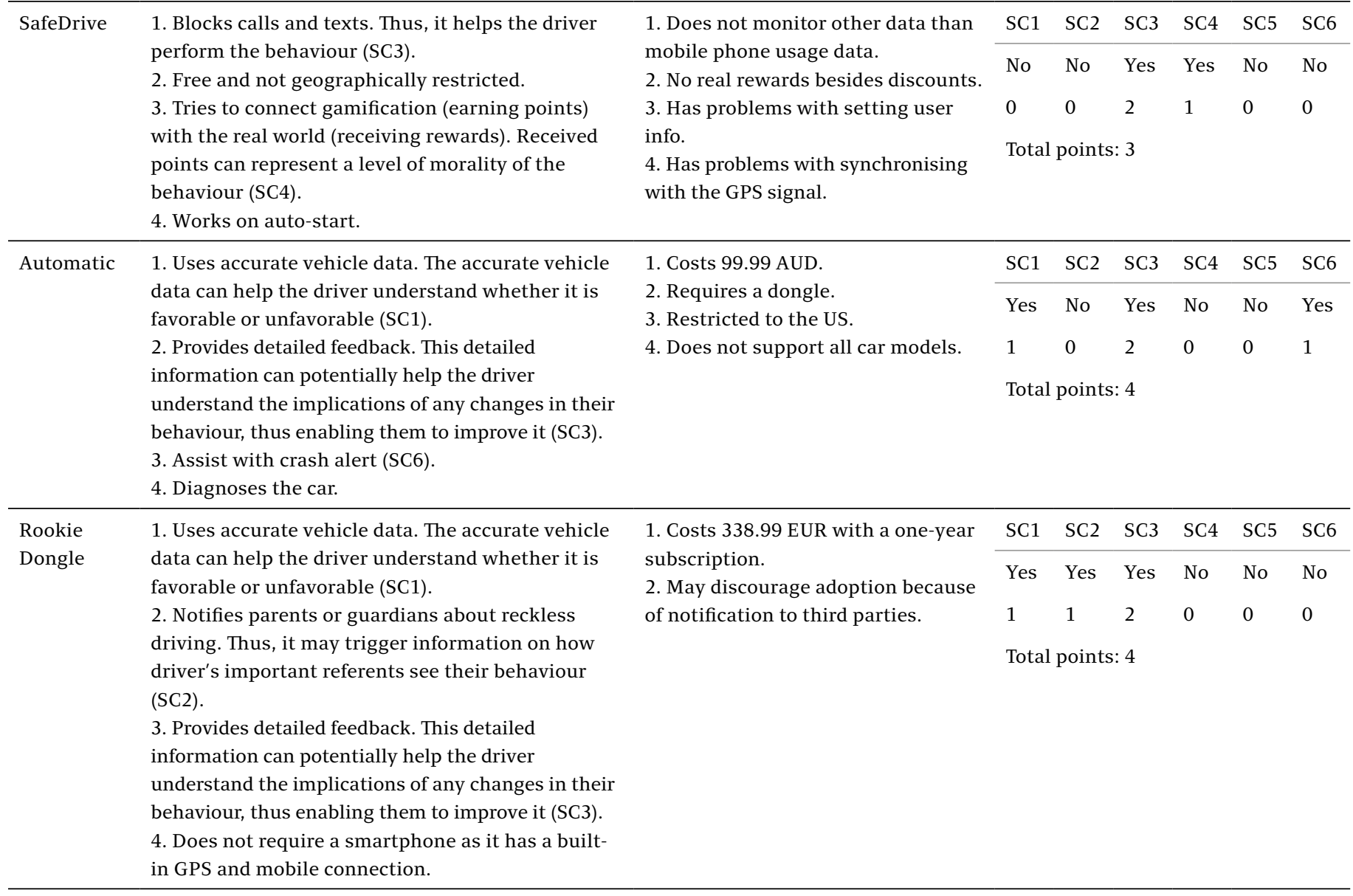

Table 2. Smartphone safe-driving apps (yes=1, no=0, double points for SC3).

Out of the six apps, "Flo - driving insights" scored the highest, 5 . Thus, it would be the initial best candidate for driving tests as established by the adopted theory-based criteria. However, theory can provide a well-informed direction, which may be challenging to implement in practical terms. To overcome known difficulties, a focus group, representing a convenience sample of academia (3 people), applied research ( 1 person) and project leaders (6 people) in the domain of awareness-raising road safety interventions for young drivers, suggested practical criteria which may boost safe-driving apps' adoption if met (Vankov, 2020) (see Table 3).

\begin{tabular}{ll}
\hline Criteria & Description \\
\hline Low-cost & $\begin{array}{l}\text { To boost adoption, it would be best if the app is free } \\
\text { for users and does not require hardware, such as } \\
\text { a dongle, in addition to the smartphone itself. }\end{array}$ \\
\hline Safety & $\begin{array}{l}\text { The app should provide live feedback to the driver } \\
\text { and run invisibly in the backgrwwound, thus, not } \\
\text { causing additional distraction. It also shall have } \\
\\
\text { a self-starting capability. }\end{array}$ \\
\hline Availability & The app shall not be geographically restricted. \\
\hline Information & $\begin{array}{l}\text { The app shall provide various types of information. } \\
\text { It shall have a web interface. It shall provide detailed } \\
\text { after-trip feedback on a Google map. It should also } \\
\text { feature user groups (i.e. proprietary leaderboards) } \\
\text { with the achievements being possible to share on } \\
\text { social media. }\end{array}$ \\
\hline
\end{tabular}

Table 3. Synthesised practical criteria for smartphone safe-driving apps (Vankov, 2020).

As presented in Table 2, "Flo - driving insights" complies with all four criteria listed in Table 3 . Thus, it might have been a good candidate for a road safety intervention. Nevertheless, those criteria might not be equally applicable to all technologies or risky behaviours. For example, simulator sickness is a known issue in simulator studies (De Winter, van Leeuwen, \& Happee, 2012). This problem seems not applicable for smartphones but persistent in virtual reality (Vankov \& Jankovszky, InPress). As a result, simulator sickness should be investigated when assessing the suitability of both driving simulators and virtual reality applications. Thus, we recommend when the theoretically-informed suitability of novel technology tools to trigger behaviour change is being assessed by experts, as discussed above, those same experts to be asked to provide opinions on potential practical criteria, too.

\section{CONCLUSION}

Available technology provides opportunities to help address social issues such as risky road behaviours. Those opportunities are vastly explored by both academia and business. However, it is not uncommon to have multiple technologies claiming to serve a similar purpose. Thus, researchers may find it challenging to select one technology over another. Furthermore, technology is often initially researched with regards to user experience and technology acceptance. Much less is known about their potential to influence behaviour.

The current article offers researchers a helpful model to choose a technology that best meets their needs. The model is grounded in TPB, thus providing a robust theoretical underpinning. At the same time, we show the model's flexibility, which can be extended depending on the specific research needs. Then, we presented how selection criteria for choosing a technology are developed based on six constructs (attitude, subjective norm, PBC, moral norm, perceived risk and peers' 
norm). Finally, we complemented the theory-based criteria with practical considerations to inform a final choice. Researchers might find the proposed approach insightful in their future work even if they choose to apply a different theory. As a result, the provided methodologically sound yet easy to implement guidance could potentially increase the quality of their future technology-based interventions.

\section{REFERENCES}

Ajzen, I. (1991). The theory of planned behavior. Organizational behavior and human decision processes, 50(2), 179-211.

Ajzen, I. (2006). Behavioral interventions based on the theory of planned behavior. In. Retrieved from https://people.umass. edu/aizen/pdf/tpb.intervention.pdf.

Armitage, C., \& Conner, M. (2001). Efficacy of the theory of planned behaviour: A meta-analytic review. British Journal of Social Psychology, 40(4), 471-499.

Aveyard, P., Cheng, K., Almond, J., Sherratt, E., Lancashire, R., Lawrence, T., ... Evans, O. (1999). Cluster randomised controlled trial of expert system based on the transtheoretical ("stages of change") model for smoking prevention and cessation in schools. Bmj, 319(7215), 948-953.

Bandura, A. (1986). Social foundations of thought and action: A social cognitive theory: Prentice-Hall, Inc.

Banks, T. D. (2008). An investigation into how work-related road safety can be enhanced. (PhD), Retrieved from http://eprints. qut.edu.au/29683/

Bazargan-Hejazi, S., Teruya, S., Pan, D., Lin, J., Gordon, D., Krochalk, P., \& Bazargan, M. (2017). The theory of planned behavior (TPB) and texting while driving behavior in college students. Traffic Injury Prevention, 18(1), 56-62.

Brookhuis, K., Waard, D., \& Samyn, N. (2004). Effects of MDMA (ecstasy), and multiple drugs use on (simulated) driving performance and traffic safety. Psychopharmacology, 173(3-4), 440-445. doi: $10.1007 / \mathrm{s} 00213-003-1714-5$

Chan, D. C. N., Wu, A. M. S., \& Hung, E. P. W. (2010). Invulnerability and the intention to drink and drive: An application of the theory of planned behavior. Accident Analysis E Prevention, 42(6), 1549-1555. doi: 10.1016/j.aap.2010.03.011

Chen, H.-Y. W., Donmez, B., Hoekstra-Atwood, L., \& Marulanda, S. (2016). Self-reported engagement in driver distraction: An application of the Theory of Planned Behaviour. Transportation research part F: traffic psychology and behaviour, 38, 151-163. doi: http://dx.doi.org/10.1016/j.trf.2016.02.003

Compeau, D. R., \& Higgins, C. A. (1995). Application of social cognitive theory to training for computer skills. Information systems research, 6(2), 118-143.

Conner, M., \& Sparks, P. (2005). Theory of planned behaviour and health behaviour. In Predicting health behaviour (Vol. 2, pp. 170-222).

Davis, R., Campbell, R., Hildon, Z., Hobbs, L., \& Michie, S. (2015). Theories of behaviour and behaviour change across the social and behavioural sciences: a scoping review. Health psychology review, 9(3), 323-344.

De Nooijer, J., Van Assema, P., De Vet, E., \& Brug, J. (2005). How stable are stages of change for nutrition behaviors in the Netherlands? Health Promotion International, 20(1), 27-32.

De Winter, J., van Leeuwen, P. M., \& Happee, R. (2012). Advantages and disadvantages of driving simulators: A discussion. Paper presented at the Proceedings of measuring behavior.

Di Noia, J., Contento, I. R., \& Prochaska, J. O. (2008). Computermediated intervention tailored on transtheoretical model stages and processes of change increases fruit and vegetable consumption among urban African-American adolescents. American journal of health promotion, 22(5), 336-341.

Diewald, S., Möller, A., Roalter, L., Stockinger, T., \& Kranz, M. (2013). Gameful design in the automotive domain: review, outlook and challenges. Paper presented at the Proceedings of the 5th International Conference on Automotive User Interfaces and Interactive Vehicular Applications.

Elliott, M., \& Thomson, J. (2010). The social cognitive determinants of offending drivers' speeding behaviour. Accident Analysis \& Prevention, 42(6), 1595-1605. doi: 10.1016/j.aap.2010.03.018

Fife-Schaw, C., Sheeran, P., \& Norman, P. (2007). Simulating behaviour change interventions based on the theory of planned behaviour: Impacts on intention and action. British Journal of Social Psychology, 46(1), 43-68.

Fishbein, M., \& Ajzen, I. (2010). Predicting and changing behavior: The reasoned action approach: Taylor \& Francis.

Fogg, B. (2009). Creating Persuasive Technologies: An Eight-Step Design Process.

Freeman, J., Liossis, P., Schonfeld, C., Sheehan, M., Siskind, V., \& Watson, B. (2005). Self-reported motivations to change and self-efficacy levels for a group of recidivist drink drivers. Addictive Behaviors, 30(6), 1230-1235. doi: http://dx.doi. org/10.1016/i.addbeh.2004.10.007

Frei, A., Svarin, A., Steurer-Stey, C., \& Puhan, M. A. (2009). Selfefficacy instruments for patients with chronic diseases suffer from methodological limitations-a systematic review. Health and quality of life outcomes, 7(1), 86.

Gold, M. A., Tzilos, G. K., Stein, L., Anderson, B. J., Stein, M. D., Ryan, C. M., . . . DiClemente, C. (2016). A Randomized Controlled Trial to Compare Computer-assisted Motivational Intervention with Didactic Educational Counseling to Reduce Unprotected Sex in Female Adolescents. Journal of pediatric and adolescent gynecology, 29(1), 26-32.

Haque, R., Clapoudis, N., King, M., Lewis, I., Hyde, M. K., \& Obst, P. (2012). Walking when intoxicated: An investigation of the factors which influence individuals' drink walking intentions. Safety Science, 50(3), 378-384. doi: https://doi.org/10.1016/i. ssci.2011.09.017

Hingson, R., Heeren, T., Levenson, S., Jamanka, A., \& Voas, R. (2002). Age of drinking onset, driving after drinking, and involvement in alcohol related motor-vehicle crashes. Accident Analysis \& Prevention, 34(1), 85-92. doi: 10.1016/S00014575(01)00002-1

Hughes, J. R., Keely, J. P., Fagerstrom, K. O., \& Callas, P. W. (2005). Intentions to quit smoking change over short periods of time. Addictive Behaviors, 30(4), 653-662.

Ifinedo, P. (2016). Examining students' intention to continue using blogs for learning: Perspectives from technology acceptance, motivational, and social-cognitive frameworks. Computers in Human Behavior. doi: http://dx.doi.org/10.1016/j. chb.2016.12.049

Kohler, C. L., Grimley, D., \& Reynolds, K. (1999). Theoretical approaches guiding the development and implementation of health promotion programs. In Handbook of health promotion and disease prevention (pp. 23-49): Springer.

Lang, Y., Wei, L., Xu, F., Zhao, Y., \& Yu, L. F. (2018). Synthesizing Personalized Training Programs for Improving Driving Habits via Virtual Reality. Paper presented at the 25th IEEE Conference on Virtual Reality and 3D User Interfaces, VR 2018 - Proceedings.

Lee, C. (1989). Theoretical weaknesses lead to practical problems: The example of self-efficacy theory. Journal of Behavior Therapy and Experimental Psychiatry, 20(2), 115-123. doi: http://dx.doi. org/10.1016/0005-7916(89)90044-X

Lee, J. D. (2007). Technology and teen drivers. Journal of Safety Research, 38(2), 203-213. doi: 10.1016/j.jsr.2007.02.008

Lennon, A., Oviedo-Trespalacios, O., \& Matthews, S. (2017). Pedestrian self-reported use of smart phones: Positive attitudes and high exposure influence intentions to cross the road while distracted. Accident Analysis E Prevention, 98, 338-347. doi: http://dx.doi.org/10.1016/j.aap.2016.10.028

Littell, J. H., \& Girvin, H. (2002). Stages of change A critique. Behavior Modification, 26(2), 223-273. 
Mackenzie, J. E. (2016). Mothers' sleepiness and driving in the postpartum period. (PhD), Retrieved from http://eprints.qut. edu.au/95190/

Mauriello, L. M., Ciavatta, M. M. H., Paiva, A. L., Sherman, K. J., Castle, P. H., Johnson, J. L., \& Prochaska, J. M. (2010). Results of a multi-media multiple behavior obesity prevention program for adolescents. Preventive medicine, 51(6), 451-456.

Miller, S. M., Shoda, Y., \& Hurley, K. (1996). Applying cognitive-social theory to health-protective behavior: breast self-examination in cancer screening. Psychological bulletin, 119(1), 70.

Oviedo-Trespalacios, O., Haque, M. M., King, M., \& Washington, S. (2016). Understanding the impacts of mobile phone distraction on driving performance: A systematic review. Transportation Research Part C: Emerging Technologies, 72, 360-380. doi: 10.1016/j.trc.2016.10.006

Oyelere, S. S., Bouali, N., Kaliisa, R., Obaido, G., Yunusa, A. A., \& Jimoh, E. R. (2020). Exploring the trends of educational virtual reality games: a systematic review of empirical studies. Smart Learning Environments, 7(1), 31. doi: 10.1186/s40561020-00142-7

Polacsek, M., Rogers, E. M., Woodall, W. G., Delaney, H., Wheeler, D., \& Rao, N. (2001). MADD victim impact panels and stages-of-change in drunk-driving prevention. Journal of Studies on Alcohol, 62(3), 344-350.

Potard, C., Kubiszewski, V., Camus, G., Courtois, R., \& Gaymard, S. (2018). Driving under the influence of alcohol and perceived invulnerability among young adults: An extension of the theory of planned behavior. Transportation research part F: traffic psychology and behaviour, 55, 38-46. doi: 10.1016/j. trf.2018.02.033

Prochaska, J. O., DiClemente, C. C., Velicer, W. F., \& Rossi, J. S. (1993). Standardized, individualized, interactive, and personalized self-help programs for smoking cessation. Health Psychology, 12(5), 399.

Prochaska, J. O., Evers, K. E., Castle, P. H., Johnson, J. L., Prochaska, J. M., Rula, E. Y., . . Pope, J. E. (2012). Enhancing multiple domains of well-being by decreasing multiple health risk behaviors: a randomized clinical trial. Population health management, 15(5), 276-286.

Prochaska, J. O., \& Velicer, W. F. (1997). The transtheoretical model of health behavior change. American journal of health promotion, 12(1), 38-48.

Quine, L., Rutter, D. R., \& Arnold, L. (2001). Persuading school-age cyclists to use safety helmets: Effectiveness of an intervention based on the Theory of Planned Behaviour. British journal of health psychology, 6(4), 327-345.

Rana, N. P., \& Dwivedi, Y. K. (2015). Citizen's adoption of an e-government system: Validating extended social cognitive theory (SCT). Government Information Quarterly, 32(2), 172-181. doi: http://dx.doi.org/10.1016/j.giq.2015.02.002

Rizzo, A., \& Koenig, S. (2017). Is Clinical Virtual Reality Ready for Primetime? Neuropsychology, 31(8), 877-899. doi: 10.1037/ $\underline{\text { neu0000405 }}$

Rutter, J., \& Quine, L. (2002). Changing health behaviour (Vol. 17): Citeseer.

Schwarzer, R., \& Renner, B. (2000). Social-cognitive predictors of health behavior: action self-efficacy and coping self-efficacy. Health Psychology, 19(5), 487.

Scott-Parker, B. (2012). A compehensive investigation of the risky driving behaviour of young novice drivers. Queensland Univeristy of Technology,

Sheeran, P., Gollwitzer, P. M., \& Bargh, J. A. (2013). Nonconscious processes and health. Health Psychology, 32(5), 460.

Siliquini, R., Piat, S. C., Alonso, F., Druart, A., Kedzia, M., Mollica, A., ... Group, T. (2010). A European study on alcohol and drug use among young drivers: the TEND by Night study design and methodology. BMC public health, 10(1), 205. doi: $10.1186 / 1471-2458-10-205$
Smedslund, J. (1978). Bandura's theory of self-efficacy: A set of common sense theorems. Scandinavian Journal of Psychology, 19(1), 1-14.

Sniehotta, F. F., Presseau, J., \& Araújo-Soares, V. (2014). Time to retire the theory of planned behaviour. In: Taylor \& Francis.

Sommer, L. (2011). The theory of planned behaviour and the impact of past behaviour. International Business Economics Research Journal, 10(1).

Stead, M., Tagg, S., MacKintosh, A. M., \& Eadie, D. (2005). Development and evaluation of a mass media Theory of Planned Behaviour intervention to reduce speeding. Health education research, 20(1), 36-50.

Steinberger, F., Schroeter, R., Foth, M., \& Johnson, D. (2017). Designing gamified applications that make safe driving more engaging. Paper presented at the Proceedings of the 2017 CHI Conference on Human Factors in Computing Systems.

Tranter, P., \& Warn, J. (2008). Relationships between interest in motor racing and driver attitudes and behaviour amongst mature drivers: An Australian case study. Accident Analysis E Prevention, 40(5), 1683-1689.

Vaezipour, A. (2018). Design and development of an in-vehicle human machine interface for eco-safe driving. $(\mathrm{PhD})$, Retrieved

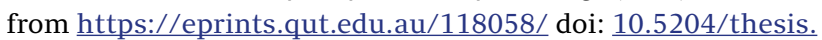
eprints. 118058

Van Duyn, M. A. S., Heimendinger, J., Russek-Cohen, E., DlClemente, C. C., Sims, L. S., Subar, A. F., . . Kahle, L. L. (1998). Use of the transtheoretical model of change to successfully predict fruit and vegetable consumption. Journal of Nutrition Education, 30(6), 371-380.

Vankov, D., \& Jankovszky, D. (InPress). Effects of using headsetdelivered virtual reality in road safety research: A systematic review of empirical studies. Virtual Reality $\mathcal{E}$ Intelligent Hardware.

Vankov, D., \& Schroeter, R. (2021). Driving under the influence of drugs or alcohol: Predicting the intentions of young drivers. Traffic Injury Prevention, 1-5. doi: $10.1080 / 15389588.2020 .1869953$

Vankov, D., Schroeter, R., \& Twisk, D. (2021a). Can't simply roll it out: Evaluating a real-world virtual reality intervention to reduce driving under the influence. PloS one, 16(4), e0250273. doi: 10.1371 /journal.pone. 0250273

Vankov, D., Schroeter, R., \& Twisk, D. (2021b). Understanding the predictors of young drivers' speeding intention and behaviour in a three-month longitudinal study. Accident Analysis \& Prevention, 151, 105859. doi: 10.1016/j. aap.2020.105859

Vankov, D. L. (2020). Smartphone apps and virtual reality as road safety interventions: Examining their real-world effects for young drivers. Queensland University of Technology, doi: 10.5204/ thesis.eprints.180754

Velicer, W. F., Redding, C. A., Paiva, A. L., Mauriello, L. M., Blissmer, B., Oatley, K., . . . Prochaska, J. O. (2013). Multiple behavior interventions to prevent substance abuse and increase energy balance behaviors in middle school students. Translational behavioral medicine, 3(1), 82-93.

Wallace, L. S., Buckworth, J., Kirby, T. E., \& Sherman, W. M. (2000). Characteristics of Exercise Behavior among College Students: Application of Social Cognitive Theory to Predicting Stage of Change. Preventive medicine, 31(5), 494-505. doi: http://dx.doi. org/10.1006/pmed.2000.0736

Ward, N. J., Otto, J., Schell, W., Finley, K., Kelley-Baker, T., \& Lacey, J. H. (2017). Cultural predictors of future intention to drive under the influence of cannabis (DUIC). Transportation research part F: traffic psychology and behaviour, 49, 215-225. doi: $10.1016 / j . \operatorname{trf} .2017 .06 .013$

Warner, H. W., \& Åberg, L. (2008). Drivers' beliefs about exceeding the speed limits. Transportation research part F: traffic psychology and behaviour, 11(5), 376-389. 
Webb, T. L., \& Sheeran, P. (2006). Does changing behavioral intentions engender behavior change? A meta-analysis of the experimental evidence. Psychological bulletin, 132(2), 249.

West, R. (2005). Time for a change: putting the Transtheoretical (Stages of Change) Model to rest. Addiction, 100(8), 1036-1039.

Yıldırım-Yenier, Z., Vingilis, E., Wiesenthal, D. L., Mann, R. E., \& Seeley, J. (2016). Relationships between thrill seeking, speeding attitudes, and driving violations among a sample of motorsports spectators and drivers. Accident Analysis E Prevention, 86, 16-22. doi: http://dx.doi.org/10.1016/j. aap.2015.09.014 